\title{
Barriers to cancer rehabilitation: healthcare professionals' perspective in Saudi Arabia
}

\author{
Barrieren für die Rehabilitation von Krebs: Die Perspektive von \\ Angehörigen der Gesundheitsberufe in Saudi Arabien
}

Authors

Amani A. Aljohi ${ }^{1}$, Fatimah M. AlKathiri ${ }^{1}$, Kawthar F. Ajaj ${ }^{2}$, Syamala Buragadda², Sanaa M. Madi ${ }^{1}$

Affiliations

1 Rehabilitation Hospital, Physical Therapy Department, King Fahad Medical City, Riyadh, Saudi Arabia

2 Department of Rehabilitation Health Sciences, College of Applied Medical Sciences, King Saud University, Riyadh, Saudi Arabia

Key words

Cancer, Rehabilitation, Barriers, Healthcare providers

Schlüsselwörter

Krebs, rehabilitation, Hindernisse, Gesundheitsdienstleister

received $\quad 09.12 .2018$

accepted 23.04.2019

Bibliography

DOI https://doi.org/10.1055/a-0901-1252

Published online: 25.6.2019

Phys Med Rehab Kuror 2019; 29: 317-322

(c) Georg Thieme Verlag KG Stuttgart · New York

ISSN 0940-6689

Correspondence

Amani A. Aljohi

Rehabilitation Hospital, Physical Therapy Department

King Fahad Medical City

11525 Riyadh

Saudi Arabia

a_aljohi@yahoo.com

\section{ABSTRACT}

Background Cancer has a major impact on societies across the world and there is a significant rise in the global cancer burden. Due to advancements in cancer diagnosis and treatment, the number of cancer survivors is increasing. However, they face physical and cognitive challenges, which may affect their quality of life. The study aims to identify current clinical practice patterns and barriers to cancer rehabilitation from the perspective of Saudi healthcare professionals.
Method All healthcare professionals providing care for cancer patients at King Fahad Medical City were invited to participate. Two semi-structured focus groups and 9 interviews were conducted. Participants were physicians and allied health professionals. The researcher led the discussions and recorded comments, facial expressions, and other non-verbal communication nuances. Content analysis was performed to identify and summarize themes.

Results Four key themes related to barriers in cancer rehabilitation are identified: healthcare providers' competencies and knowledge, communication barriers, limited rehabilitation services for cancer patients, and patient- and family-related barriers.

Conclusion The study identifies current clinical practice patterns and various barriers to cancer rehabilitation from Saudi health care professionals' perspective. The findings may help policy makers and stake holders to design effective rehabilitation guidelines for cancer rehabilitation.

\section{ZUSAMMENFASSUNG}

Hintergrund Krebs hat weltweit erhebliche Auswirkungen auf die Gesellschaften, wobei ein deutlicher Anstieg der weltweiten Krebsbelastung zu verzeichnen ist. Dank der Fortschritte bei der Diagnose und Behandlung von Krebs steigt die Zahl der Personen, die den Krebs überleben. Allerdings haben sie mit körperlichen und kognitiven Herausforderungen zu kämpfen, die ihre Lebensqualität beeinträchtigen können. Das Ziel der Studie ist es, aktuelle Strukturen der klinischen Praxis und die Hindernisse, die bei Krebserkrankungen einer Rehabilitation im Wege stehen, aus Sicht saudischer medizinischer Fachkräfte zu identifizieren.

Methode Alle medizinischen Fachkräfte, die Krebspatienten in der King Fahad Medical City betreuen, waren zur Teilnahme eingeladen. Es gab 2 semistrukturierte Fokusgruppen, wobei neun Befragungen durchgeführt wurden. Die Teilnehmer waren Ärzte und Angehörige sonstiger Gesundheitsberufe. Der Forscher leitete die Diskussionen und notierte Kommentare, Mimik und sonstige Nuancen nonverbaler Kommunikation. Die Inhaltsanalyse wurde durchgeführt, um Themen zu identifizieren und zusammenzufassen. 
Ergebnisse in Bezug auf die Hindernisse, die einer Rehabilitation bei Krebserkrankungen im Wege stehen, wurden vier zentrale Themen identifiziert: die Kompetenzen und Kenntnisse der Gesundheitsdienstleister, Kommunikationshindernisse, begrenzte Rehabilitationsleistungen für Krebspatienten sowie patienten- und familienbezogene Hindernisse.
Fazit Die Studie identifiziert aktuelle Strukturen der klinischen Praxis sowie verschiedene Hindernisse bezüglich der Rehabilitation bei Krebserkrankungen, dies aus der Sicht saudischer medizinischer Fachkräfte. Die Ergebnisse können den Entscheidungsträgern und Beteiligten helfen, effektive Richtlinien für die Rehabilitation bei Krebserkrankungen zu entwickeln.

$\begin{array}{ll}\text { ABBREVIATIONS } \\ \text { MD } & \text { Medicine } \\ \text { AHP } & \text { Allied health professional } \\ \text { PMR } & \text { Physical medicine and rehabilitation } \\ \text { OT } & \text { Occupational therapist } \\ \text { PT } & \text { Physical therapist. }\end{array}$

\section{Introduction}

Cancer has a major impact on the health of individuals worldwide, including in the Kingdom of Saudi Arabia. In Saudi Arabia, there were 15,807 cases of cancer in 2014 [1]. The number of cancer survivors is increasing, primarily as a result of advances in cancer treatment and earlier diagnosis. While cancer patients are living longer, many have resultant physical and cognitive disabilities, which may impair their quality of life. Indeed, studies have shown a high prevalence of functional impairments among cancer patients with a wide range of diagnoses and treatment situations [2-7]. In an effort to improve the quality of life of cancer survivors, increasing attention has been given to improving functional recovery following treatment. Rehabilitation has been recognized as a strategy for restoring patients' functional independence and improving their psychological functioning $[4,8,9]$. Moreover, it has been suggested that identification of cancer-related impairments and intervention through rehabilitation therapies across the care continuum may be more effective in restoring functional deficits when done early than if impairments are allowed to worsen over time [10].

The evidence in favour of cancer rehabilitation is growing and studies in general cancer populations have demonstrated that it is beneficial in the management of cancer-related fatigue [11], psychological distress [12], and pain [13, 14]. However, studies of barriers to rehabilitation services are lacking, while poor knowledge of the benefits of rehabilitation services for cancer patients [15] and low awareness in the healthcare community have limited the number of admissions to rehabilitation programmes relative to the total cancer population $[16,17]$. The increasing number of cancer patients combined with the growing need for rehabilitation may result in increased utilization of rehabilitation services. In addition, no studies have examined rehabilitation services for cancer survivors from the perspective of healthcare professionals in Saudi Arabia. The current study therefore aimed to identify current clinical practice patterns and barriers to cancer rehabilitation from the perspective of Saudi healthcare professionals.

\section{Methods}

\section{Participants and setting}

The study was conducted at the Comprehensive Cancer Centre (CCC) of the King Fahad Medical City (KFMC), which is located in the centre of Riyadh, the capital city of Saudi Arabia, and is considered to be the largest and most advanced medical complex in the country, with a total capacity of 1095 beds. The CCC offers services to cancer patients including radiation oncology, medical oncology, hematology, pediatric oncology, and palliative care. All study participants were professionals working at the CCC, comprising oncologists, allied healthcare professionals (physical therapists, occupational therapists), medical social workers, psychologists, and physiatrists providing care for cancer patients with a minimum of three years of experience and able to speak English. The IRB Committee of KFMC (IRB00010471) approved the study.

\section{Recruitment}

A recruitment poster was sent via email to all healthcare professionals working at the CCC. Potential participants were identified by department heads, who also gave each participant an information sheet about the study and asked them to consider participating. Those interested were asked to provide their contact details to the researcher.

\section{Focus groups/interviews}

Semi-structured focus groups and interviews were conducted with various healthcare professionals to identify barriers to the rehabilitation of cancer patients and examine them in detail. Two focus groups were conducted, each having 6-8 participants. The researcher led the discussion and recorded comments, facial expressions, and other non-verbal communication nuances. A set of questions, based on the area of research, the researcher's clinical experience, and a pilot focus group, was used as a guide during the focus groups and interviews. Questions were developed specifically to give participants the opportunity to talk about their individual experiences [18]. During the focus group sessions, the research assistant took notes and aimed to capture participants' exact words, nonverbal cues, and behaviour without interrupting the discussion. To assure the accuracy of the data, the focus group sessions were audio-recorded.

\section{Data management and protection}

All sources of data, namely digital audio recordings, field notes, and written transcripts, were stored securely, as were the signed consent forms. No personal identifiers were used on data collection forms or audio recordings; participants were identified by pseudo- 
nyms and codes in the interview records, field notes, and transcripts.

\section{Data analysis}

The researcher read and re-read the transcriptions in detail to identify patterns, then assigned codes to different pieces of text and identified common themes in the responses to key questions. Finally, content analysis was conducted to identify and summarize the themes. Initially, several themes were identified. However, after careful consideration of the context of the focus group and interview discussions, four main themes emerged.

\section{Results}

\section{Description of participants}

Two focus groups and nine semi-structured interviews were conducted at the KFMC Rehabilitation Hospital and the CCC. Participants were 10 physicians (oncologists, hematologists, palliative care physicians, orthopedic oncologists, and physiatrists) and 12 allied health professionals (physical therapists, occupational therapists, social workers, spiritual counsellors, and psychologists). Participants' demographic characteristics are shown in $>$ Table 1.

\section{Key themes}

Four key themes related to barriers to cancer rehabilitation were identified. These were: 1 ) healthcare providers' competencies and knowledge, 2) communication barriers, 3) limited rehabilitation services for cancer patients, and 4) patient- and family-related barriers. Each theme is illustrated below with excerpts from participants' responses.

\section{Theme 1: Healthcare providers' competencies and knowledge}

The majority of medical oncologists and hematologists believed that a lack of awareness of rehabilitation services and facilities reduced the utilization of rehabilitation services for oncology cases.
"I must acknowledge that among physicians there is a lack of knowledge or an underestimation of the need for rehab and exercise programmes. I think there should be increased awareness of this among medical and nursing teams". MD-7

Some also said that inadequate knowledge of the complications and treatment of cancer made it challenging rehabilitation therapists to set goals and plan interventions. As the complexity of cancer cases was a major concern, this challenge required highly trained rehabilitation clinicians in various specialties. However, some of the rehabilitation physicians were reluctant to accept oncology cases, due to a lack of subspecialty training for cancer rehabilitation and insufficient training to treat cancer patients.

Furthermore, there was little evidence of the effect of rehabilitation on the prognosis for cancer patients.

“We don't have studies that address cancer prognosis from the rehab point of view". MD-2

Burnout was mentioned as a burden among healthcare professionals dealing with cancer cases, especially patients with advanced cancer.

Rehabilitation and oncology professionals clearly felt that workforce shortages played a role in limiting timely oncology rehabilitation, asserting that the provision of collaborative oncology rehabilitation programmes relied on the availability of subspecialty therapists, physicians, psychologists, psychiatrists, and dietitians.

“...we should also develop an oncology rehab programme and a specific ward for oncology should be planned. To have collaboration between the oncology and rehab departments we need more professional staff and rehab physicians who specialize in this area, because the programme needs therapists, psychologists, and peer support". AHP-6

- Table 1 Demographic characteristics of participants.

\begin{tabular}{|c|c|c|c|c|c|}
\hline Professions & & $\begin{array}{l}\text { Range of age } \\
\text { (years) }\end{array}$ & $\begin{array}{l}\text { Gender } \\
\text { (female/male) }\end{array}$ & $\begin{array}{l}\text { Range of years of } \\
\text { experience }\end{array}$ & $\begin{array}{l}\text { Years of experience } \\
\text { with cancer patient }\end{array}$ \\
\hline \multirow{5}{*}{$\begin{array}{l}\text { Allied health } \\
\text { professional } n=12\end{array}$} & $\mathrm{PT}(\mathrm{n}=4)$ & $26-55$ & $(3 / 1)$ & $(4-34)$ & $(3-16)$ \\
\hline & OT $(n=4)$ & & $(2 / 2)$ & & \\
\hline & Psychologist $(n=2)$ & & $(0 / 2)$ & & \\
\hline & Spiritual consoler $(n=1)$ & & $(0 / 1)$ & & \\
\hline & Social therapist $(n=1)$ & & $(1 / 0)$ & & \\
\hline \multirow[t]{4}{*}{ Physician $n=10$} & $\begin{array}{l}\text { Hematology and } \\
\text { oncology }(n=5)\end{array}$ & $26-45$ & $(2 / 3)$ & $(6-15)$ & $(3-11)$ \\
\hline & Palliative $(n=1)$ & & $(0 / 1)$ & & \\
\hline & $\begin{array}{l}\text { orthopedic oncology } \\
(n=1)\end{array}$ & & $(0 / 1)$ & & \\
\hline & Physiatrist $(n=3)$ & & $(1 / 2)$ & & \\
\hline
\end{tabular}




\section{Theme 2: Communication barriers}

Communication difficulties among healthcare providers were found to be major barriers to using cancer rehabilitation services. Many participants reported that healthcare providers tended to use patients as channel of communication between the primary team and others. Communication difficulties were said to arise because of busy schedules, conflicts between the primary and rehabilitation teams, the unavailability of healthcare team members on the cancer ward, and lengthy processes to accept or reject a case.

"It is very difficult to reach the physical medicine and rehabilitation team and it takes a long time to assess the patient". MD-7

The other causes for lack of communication were language barriers (where healthcare providers spoke a language other than Arabic) and sociocultural issues that may lead to different expectations from patients related to functional status. Moreover, disagreements between physicians within the oncology team increased the difficulty of referring some patients to rehabilitation services.

Physiatrists spoke of their experience regarding diagnosis and prognosis, and mentioned that most patients were transferred to rehabilitation without enough information about their diagnosis or prognosis. Participants reported that the primary team often failed to communicate appropriately with the PMR team regarding the treatment plan, making it difficult to decide on the best time for rehabilitation admission. Therefore, they recommended implementing a multidisciplinary team approach or regular meetings to discuss patients' status in order to improve rehabilitation services.

"All team members should be involved in goal-setting". MD-3

Additionally, participants expressed the belief that communication skills are one of the essential competencies of oncology physicians and that they needed to improve from the perspective of allied health professionals, to meet the psychological demands of the patients.

\section{Theme 3: Limited rehabilitation services/facilities for} cancer patients

All participants agreed that the number of publicly funded rehabilitation hospitals was limited in Saudi Arabia. The one at KFMC was the only one in Riyadh; therefore, the waiting time for admission was very long. They also highlighted the difficulties arising from the lack of a cancer rehabilitation unit; for example, one of the oncologists stated that the rejection rate for cancer patients was high due to the limited number of beds. Participants also recommended having a specialized rehabilitation unit for cancer patients.

"The PMR team should have specific beds for cancer patients, at least two or three if not more, so we can refer early and they can take patients early". MD-7

Participants highlighted the need for the appropriate equipment for cancer patients to improve their quality of life. Participants highlighted the challenges that they faced when they requested this equipment, such as delays in delivery and inappropriate prescription. These could lead to delayed discharge and increased waiting times. Participants also stated that the major barrier, mentioned by their patients, was the excessive length of waiting times to be transferred from the CCC to the rehabilitation hospital or to be accepted for outpatient physical therapy.

"I give them an urgent outpatient referral to be seen next week and they give them an appointment after two weeks, which means the patient will have to wait for ten days without a home visit and without physiotherapy". MD-4

Rehabilitation hospital acceptance criteria were reported as not practical and participants complained that some rejection referrals were not being explained to the team, which led to confusion for patients and their families. One participant saw it as a potential failure in the system that no justification was required for the rejection of a referral. Such a rejection would sometimes depend solely on the PMR background and one participant reported a case where a referral was rejected three times, then eventually accepted when resent for a fourth time.

Many participants recommended having a model of care for cancer patients to provide the best rehabilitation service, which might improve the quality of care and reduce the length of stay.

"There should be some kind of agreement, a significant change in the model of care and referring system in order to overcome these problems". MD-3

\section{Theme 4: Patient barriers}

Participants identified the patient's medical status/condition as a major barrier to rehabilitation. Pain, fracture, fatigue, and physical deconditioning were factors that contributed strongly to patients' feelings of difficulty in engaging in rehabilitation. Participants also reported that patients often refused to participate in exercise programmes if they were in pain. This could be related to patients' fear of the consequences of exercising. Medical complications frequently occurred in the postoperative period.

"There are number of cancers that could have a significant impact on patients' neurological status, especially tumours that involve the brain and spinal cord, as well as those patients who require a long course of hospital treatment and ultimately will have deconditioning and muscular disorders". MD-1

Participants pointed out that the side effects of cancer treatment, including chemotherapy and radiation therapy, made rehabilitation challenging for both healthcare providers and patients.

"So this is quite a challenging kind of programme. We can find a plethora of barriers and patients with chemotherapy or radiation therapy will probably have fatigue". AHP-5

Participants also believed that patients receiving inpatient rehabilitation had a significant rate of interruptions of their rehabilitation programme, often being transferred back to the main hospital or another acute hospital to receive chemotherapy or treatment for medical complications. 
"Follow-up is difficult; sometimes the programme is interrupted because of medical complications, or receiving chemotherapy or radiation. So when the patient comes back to rehabilitation, then we need to set new goals and new programmes". MD-2

Poor prognosis was another key issue raised by all participants, meaning that patients whose prognosis was poor were either not considered appropriate for rehabilitation or were not prioritized, due to limited rehabilitation resources.

\section{Discussion}

This qualitative study is the first in Saudi Arabia to explore the barriers to oncology rehabilitation from the perspective of healthcare providers. Its results will help to facilitate the future provision of rehabilitation services for cancer patients during or after treatment. The thematic analysis indicates that the extent of healthcare providers' knowledge negatively affected the provision of rehabilitation to the cancer population. Participants identified poor awareness of rehabilitation services as a major obstacle to cancer rehabilitation. The findings of this study are consistent with those of previous studies, which found that $85 \%$ of medical oncologists had insufficient awareness of available rehabilitation facilities and that approximately $88 \%$ of physicians lacked knowledge of the benefits of oncology rehabilitation $[15,19]$.

On the other hand, physiatrists lacked experience and subspecialty training, which they believed might result in delayed referrals of cancer patients to rehabilitation services. Physiatrists found that cancer patients were challenging to manage for several reasons, such as symptom management, the stage of cancer, and psychological factors. The current challenge for rehabilitation professionals is to manage patients with advanced stage of cancer who need palliative care, although they have poor prognosis [20]. Silver et al. conclude that establishing high-quality comprehensive care for oncology cases requires a strong partnership between rehabilitation and palliative care [21]. Since palliative care plays a role in symptom management, while rehabilitation deals with impairment management, these services together help to improve quality of life. Silver and Gilchrist emphasize the importance of developments in clinical research for the advancement of various aspects of cancer rehabilitation [22].

The results of the current study indicate that staff scarcity was another barrier to the use of oncology rehabilitation. A previous study by Mohd Nordin et al. identified staff shortages as a concern for the provision of continuity of care and rehabilitation in many developing countries, such as Malaysia [23]. Similarly, Woo et al. found that shortage of staff had a negative impact on the functional improvement of rehabilitation services [24].

Physicians who are unfamiliar with the features of rehabilitation [25] have identified primary barriers to rehabilitation care as lack of identification of patient problems and lack of appropriate referrals. It is unsurprising that participants in the present study identified the extent of familiarity with systems as one of the main barriers, since oncology and rehabilitation services may different considerably in the systems they operate and the patient procedures they follow. Moreover, health professionals in the two services often do not know each other and may not have sufficient contact to discuss the prognosis of cancer patients [24]. The absence of a uniform and cooperative referral system, the inadequacy of governmental support, both structural and financial, and the shortage of medical equipment are major barriers to providing rehabilitation services to cancer patients [15].There is an intense need for stakeholders' guidelines and priorities in rehabilitation [26]. On the other hand, there is a need for community-based rehabilitation centres and the training of family members in order to enable patients to access and benefit from long-term rehabilitation [23]. Unfortunately, there are few community-based rehabilitation centres in Saudi Arabia. The high number of respondents from an advanced medical centre of the country is the main strength of the study. However, there are a few limitations. Health care professionals discussed the factors related to cancer rehabilitation in the local context. Secondly, all the health care clinics across the region were not included in the study. Hence the results of our study cannot be generalized to the other health care settings.

\section{Conclusions}

This study has explored Saudi healthcare professionals' perspectives about cancer rehabilitation. It identified several barriers to provision of oncology care which must be addressed to improve clinical practice patterns and facilitate optimal and effective rehabilitation services for cancer patients in Saudi Arabia. The results of the study may help the stake holders and the policy makers to design effective rehabilitation guidelines for cancer patients in the kingdom.

\section{Acknowledgement}

The authors thank all the healthcare professionals' of Comprehensive Cancer Centre and Rehab hospital, KFMC for their participation in this study.

\section{Conflict of Interest}

The authors declare no conflict of interest.

\section{References}

[1] Ferlay J. GLOBOCAN 2008 v2. 0, Cancer incidence and mortality worldwide: IARC CancerBase No. 10. http://globocan. iarc. fr. 2010

[2] Cheville AL, Beck LA, Petersen TL et al. The detection and treatment of cancer-related functional problems in an outpatient setting. Support Care Cancer 2009; 17: 61-67

[3] Cheville AL, Troxel AB, Basford JR et al. Prevalence and treatment patterns of physical impairments in patients with metastatic breast cancer. J Clin Oncol 2008; 26: 2621

[4] Silver JK, Baima J. Cancer prehabilitation: an opportunity to decrease treatment-related morbidity, increase cancer treatment options, and improve physical and psychological health outcomes. American journal of physical medicine \& rehabilitation 2013; 92: 715-727

[5] Stout NL, Binkley JM, Schmitz KH et al. A prospective surveillance model for rehabilitation for women with breast cancer. Cancer 2012; 118: (S8) 2191-2200 
[6] Crevenna R. Support Care Cancer 2015; 23: 3407. https://doi. org/10.1007/s00520-015-2977-2971

[7] Thorsen L, Gjerset GM, Loge JH et al. Cancer patients' needs for rehabilitation services. Acta Oncologica. 2011; 50: 212-222

[8] Eyigor S. Physical activity and rehabilitation programs should be recommended on palliative care for patients with cancer. J Palliat Med 2010; 13: 1183-1184.9

[9] Javier NS, Montagnini ML. Rehabilitation of the hospice and palliative care patient. J Palliat Med 2011; 14: 638-648

[10] Silver J, Baima J, Mayer R. Impairment-driven cancer rehabilitation: an essential component of quality care and survivorship. CA Cancer J Clin 2013; 63: 295-317

[11] Cramp F, Byron-Daniel J. Exercise for the management of cancer-related fatigue in adults. Cochrane Database Syst Rev 2012; 11: CD006145

[12] Vodermaier A, Linden W, Siu C. Screening for emotional distress in cancer patients: a systematic review of assessment instruments. Journal of the National Cancer Institute 2009; 101: 1464-1488

[13] Haydon MD, Stanton AL, Ganz PA et al. Goal disturbance in early-stage breast cancer survivors. Journal of Psychosocial Oncology 2019; Jan 24 $1-6$

[14] Wilkinson S, Barnes K, Storey L. Massage for symptom relief in patients with cancer: Systematic review. J Adv Nurs 2008; 63: 430-439

[15] Yang EJ, Chung SH, Jeon JY et al. Current practice and barriers in cancer rehabilitation: perspectives of Korean physiatrists. Cancer Res Treat 2015; 47: 370-378

[16] Huang ME, Sliwa JA. Inpatient rehabilitation of patients with cancer: efficacy and treatment considerations. PM R. 2011; 3: 746-757

[17] Stubblefield MD, Hubbard G, Cheville A et al. Current perspectives and emerging issues on cancer rehabilitation. Cancer 2013; 119: 2170-2178.18
[18] Krueger RA, Casey MA.Focus groups A practical guide for applied research. 2014 Sage publications;

[19] Spill GR, Hlubocky F], Daugherty CK. Oncologists' and physiatrists' attitudes regarding rehabilitation for patients with advanced cancer. PM R. 2012; 4: 96-108

[20] Smith SR, Zheng JY. The intersection of oncology prognosis and cancer rehabilitation. Current physical medicine and rehabilitation reports 2017; 1: 46-54

[21] Silver JK, Raj VS, Fu JB et al. Cancer rehabilitation and palliative care: critical components in the delivery of high-quality oncology services. Support Care Cancer 2015; 23: 3633-3643.23

[22] Silver JK, Gilchrist LS. Cancer rehabilitation with a focus on evidence-based outpatient physical and occupational therapy interventions. Am J Phys Med Rehabil 2011; 90: S5-S15

[23] Mohd Nordin NA, Aziz NA, Abdul Aziz AF et al. Exploring views on long term rehabilitation for people with stroke in a developing country: findings from focus group discussions. BMC Health Serv Res 2014; 14 : 118

[24] Woo J, Chan SY, Sum MW et al. In patient stroke rehabilitation efficiency: influence of organization of service delivery and staff numbers. BMC Health Serv Res 2008; 8: 86

[25] Paul K, Buschbacher R. Cancer rehabilitation: increasing awareness and removing barriers. Am J Phys Med Rehabil 2011; 90: S1-S4

[26] Westby MD, Backman CL. Patient and health professional views on rehabilitation practices and outcomes following total hip and knee arthroplasty for osteoarthritis: a focus group study. BMC Health Serv Res 2010; 10: 119 